\section{Materials Research Society of India Holds Second Annual General Meeting}

The Materials Research Society of India is holding its Second Annual General Meeting February $9-10,1991$ at the National Physical Laboratory in New Delhi. The meeting is being hosted by the society's New Delhi Local Chapter.

The meeting will feature a plenary address, invited talks, poster sessions, and a panel discussion. The invited talks and poster sessions will focus on biomaterials, building materials, ceramics and glasses, composites, electronic materials, magnetic materials, metals, polymers, processing technologies, and thin films.

For information about the meeting, contact: S.K. Joshi or B.K. Das, National Physical Laboratory, Dr. K.S. Krishnan Road, New Delhi 110012, India; telephone 91-11581440 or 5726058; fax 91-11-5721436.

\section{International Conference on Advanced Materials Slated for Strasbourg}

The International Conference on Advanced Materials (ICAM - 91), cosponsored by the International Union of Materials Research Societies, European Materials Research Society, Materials Research Society of Japan, and the Materials Research Society, will be held May 27-31, 1991 in Strasbourg, France in conjunction with the Spring Meeting of the European Materials Research Society. The aim of the conference is to provide an overview of the status of key issues in materials science.

The international organizing committee, chaired by Minko Balkanski (France) includes: K.J. Bachmann (United States), L. Correra (Italy), H-L. Hwang (Taiwan, China), L. Nicolais (Italy), C. Schwab (France), T. Takahashi (Japan), H.L. Tuller (United States), and E. Yasuda (Japan). The international advisory committee is being chaired by R.P.H. Chang (United States).

Papers reporting on recent progress in research and development for advanced materials are being soliciated under four symposium topics. Abstracts are due March 1, 1991 and should be sent to the chairs identified below.

\section{High Temperature Superconductor Thin Films}

Chairs: L. Correra (Italy), T. Venkatesan (USA).

This symposium, which will focus on recent developments and improvements in high Tc superconductor thin films, aims to highlight insights in both basic aspects and the applied issues of research. Contribu- tions are solicited in the following areas: substrates and multilayers for deposition, film preparation, structural characterization, physical properties, material modification, applications, and other areas appropriate to the symposium's theme.

Submit abstracts to: L. Correra, CNR Istituto LAMEL, Via Castagnoli 1, 40126 Bologna, Italy; telephone 39-51-287911; fax $39-51-264829$ or 229702 .

\section{Solid State lonics}

\section{Chairs: M. Balkanski (France),}

T. Takahashi (Japan), H.L. Tuller (USA).

This symposium will give particular attention to fast ion conducting materials (crystalline, glassy, and polymeric electrolytes), and to electrode materials exhibiting mixed ionic and electronic conduction (of great interest for cation insertion in batteries and oxygen exchange in fuel cells and sensors). Topics include: fast ion transport (fundamentals), physics of ion insertion, crystalline ion conductors, glasses (fast ion conductors), polymer electrolytes, mixed conductors (including HTC cuprates), and applications. Submit abstracts to: $\mathrm{M}$. Balkanski, Laboratoire de Physique des Solides, de l'UniversitéPierre et Marie Curie, Tour 13 - 2ème étage, 4, Place Jussieu, 75252 Paris Cedex 05, France; telephone 33-1-44275894; fax 33-1-44275896.

\section{Non-Stoichiometry in \\ Semiconductors}

Chairs: K.J. Bachmann (USA), H-L. Hwang (Taiwan, China), C. Schwab (France).

This symposium will concentrate on semiconductors for which the physical arrangement of lattice points is ordered (enough for epitaxial growth to be possible) but the chemical composition is disordered (i.e., deviation from stoichiometry or molecularity). Papers are soliciated on: improved growth methods for high quality (non)stoichiometric materials (crystals, films, epitaxial layers and heterostructures); "precise" compositional and traceelemental determinations (physical and chemical) and their relations to material properties; defect identification, both theory and experiment on electronic structures; characterization, including $x$-ray diffraction, photoluminescence and photoluminescence excitation spectroscopy, $\mathrm{Ra}$ man spectroscopy, electrical and optical properties (especially their relations to (non)stoichiometry); and stoichiometry control and device making such as ultrahigh brightness LED and high-power laser, highly efficient solar cells and nonlinear optical devices, etc.

Submit abstracts to: Huey-Liang
Hwang, Department of Electrical Engineering, National Tsing Hua University, 101 Kuang Fu Road Section 2, Hsinchu, Taiwan 30043; telephone 886-35719912; fax 886-35-719910.

\section{Composite Materials}

Chairs: A.T. Di Benedetto (USA),

L. Nicolais (Italy), E. Yasuda (Japan).

This symposium aims to bring together active scientists from industry and academia who have a direct interest in seeing work in composite materials develop beyond existing boundaries. Papers are solicited on: mechanical properties, viscoelastic properties, environmental effects, durability, weak and fraction mechanics, theoretical aspects, ceramic-based composites, and general aspects.

Submit abstracts to L. Nicolais, Dipartimento di Ingegneria dei Materiali e Produzione, Facolta di Ingegneria, Universita di Napoli, Ple Tecchio, 80125 Napoli, Italy; telephone 39-81-7682400; fax 39-81-7682404.

\section{For More Information}

For more information about this meeting, contact: M. Balkanski, Laboratoire de Physique des Solides, de l'Université Pierre et Marie Curie, Tour 13 - 2ème étage, 4, Place Jussieu, 75252 Paris Cedex 05, France; 33-1-44275894; fax 33-1-44275896.

\section{E-MRS Spring Meeting to Feature 5 Symposia, TEM Summer School}

The 1991 Spring Meeting of the European Materials Research Society is scheduled for May 28 - 31, 1991 at its usual venue, the Council of Europe and European Parliament, Strasbourg, France. This year's meeting is being held in conjunction with the International Conference on Advanced Materials (ICAM - 91, May 27 - 31) and will feature five symposia, poster sessions, an equipment exhibit, and a Summer School on the Transmission Electron Microscopy of Materials.

Papers are being solicited for the symposia described below. Abstracts are due March 1, 1991, and should be sent to the symposium organizers.

\section{New Materials, Physics and Technologies for Micronic Integrated Sensors}

This three-day symposium has been organized to promote scientific exchanges on new materials for sensors. The main topics are as follows: new materials and hardware (metals, semiconductors, polymers, superconductors); modeling and specific 
CAD tools (device and process modeling); and basic mechanism analysis, including physical aspects (optical and transport properties, mechanical and thermal effects, electronic processes in low dimensional systems) and chemical aspects (reactional chemical mechanisms at the interface, exchange of chemical species and electrical charges, membrane anchoring and deposition of material at the surface, chemical treatment of surfaces, grain boundaries).

Submit abstracts to J.L. Robert, Universite de Montpellier II, Sciences et Techniques du Languedoc, Place Eugene Bataillon, F-34095 Montpellier Cedex 05, France; telephone 33-67-143794; fax 33-67543079.

\section{High Energy lon Implantation}

This three-day symposium will survey the status of ion implantation with $\mathrm{MeV}$ energies. The emphasis will be on basic problems such as distribution of dopant and defects; annealing and activation; characterization of implanted layers in semiconductors, metals, and other materials; and applications in optoelectronics and semiconductor devices. A limited number of papers on machine considerations will also be welcome.

Submit abstracts to: J. Gyulai, Joint Chair for Experimental Physics, Techn. University Dub. and Central Research Institute for Physics, P.O. Box 49, H-1525 Budapest, Hungary; telephone 36-1-695165; fax 36-11550694. S.U. Campisano, Universita di Catania, Departimento di Fisica, 57, Corso Italia, 1-95129 Catania, Italy; telephone 3995-7195421; fax 39-95-383023.

\section{lon Beam Synthesis of Compound and Elemental Layers}

This three-day symposium will cover the science and technology of compound formation by ion beam synthesis with the aim of broadening the discussions into new areas. Topics include: implantation of reactive ions for compound formation; implantation of nonreactive ions for element layers; synthesis of dielectric layers in semiconductors; synthesis of metal silicide layers; chemical and microstructural analy- sis; altered layers formed during sputter depth profiling; SIMOX technology and applications including exotic devices; computer modeling; and electrical properties of ion beam synthesized layers.

Submit abstracts to: P.L.F. Hemment, Department of Electrical and Electronic Engineering, University of Surrey, Guildford, GU25XH, United Kingdom; telephone 44483-509144; fax 44-483-34139. J.A. Kilner, Department of Materials, Imperial College, London, SW7 2BP, United Kingdom; telephone 4471-2258701; fax 4471-5847596.

\section{Laser Surface Processing and Characterization}

This four-day symposium will cover all aspects of laser materials processing. Surface, interface and thin-film reactions of dielectrics, semiconductors and superconductors, metals, and organic and biological materials will be emphasized in terms of fundamental understanding and assessing criteria for practical applications. Topics include: new organometallic precursors for surface processing; two-step processes; deposition growth, doping and patterning of thin films; ablation, etching and cutting; interface control and multilayers; surface characterization techniques; kinetic studies of surface reactions; process diagnostics and in-situ analysis; novel approaches for integrated processing; and industrial applications and device fabrication.

Submit abstracts to: Ian W. Boyd, Electronic and Electrical Engineering, University College London, Torrington Place, London WC1E 7JE, United Kingdom; telephone 4471-3807304; fax 4471-3874350. Michael Stuke, Max Planck Institut für Biophysicallische Chemie, P.O. Box 2841, D-3400 Göttingen, Germany; telephone 49-551-201338; fax 49-551-201330 or 530 .

\section{Nuclear Methods in Semiconductor Physics}

This three-day symposium will highlight recent developments in nuclear techniques applied to semiconductors. The emphasis will be on methods combining ion beam analysis with special techniques for characterizing point defects, precipitate formation, and structural changes. Topics include: $\mathrm{MeV}$ ion beam methods (Rutherford backscattering, nuclear reaction analysis, particle-induced $x$-ray emission, elastic recoil detection, charged particle activation, channeling, stopping power measurements); hyperfine interaction methods (Mössbauer spectroscopy, perturbed angle correlations, nuclear magnetic resonance, muon spin resonance, electron nuclear double resonance); and other methods (position annihilation, $\mathrm{e}+$, e- alpha emission channeling, and microbeam and diffusion methods).

Submit abstracts to: G. Langouche, IKS KU Leuven, Celestijnenlaan 200 D, B-3001 Leuven, Belgium; telephone 32-16-201015; fax 32-16-291959. J.C. Soares, Centro de Fisica Nuclear, Universidade de Lisboa, Av. Gama Pinto 2, P-1699 Lisboa Codex, Portugal; telephone 351-17950790; fax 351-1765622. J.P. Stoquert, CRN, Laboratoire PHASE, B.P. 20, F-67037 Strasbourg Cedex, France; telephone 33-88-286252; fax 33-88-280990.

\section{Summer School on TEM of Materials}

Scheduled from May 27 to May 31, this summer school on the transmission electron microscopy of materials will present a brief, comprehensive account of advances in techniques. Topics will include: diffraction contrast, high resolution imaging, convergent beam electron diffraction, $x$ ray microanalysis, and electron energy loss spectrometry. Practical demonstrations are planned, and the class is limited to 25 participants. For information contact either of the chairs: Aldo Armigliato, CNR - Istituto LAMEL, Via Castagnoli, 1, I-40126, Bologna, Italy; telephone 39-51-287932; fax 3951-226194. André Rocher, CEMES - LOE, CNRS, 29, rue Jeanne Marvig, F-31400 Toulouse, France; telephone 33-61-526596; fax 33-61-550833.

\section{For General Information}

For other information about the $1991 \mathrm{E}$ MRS Spring Meeting, contact: Paul Siffert, CRN, B.P. 20, F-67037 Strasbourg Cedex, France; telephone 33-88-286543; fax 33-88280990.

\section{Washịngton Materials Forum: Superconductors and Semiconductors February 28 - March 1, 1991 - Washington, DC \\ Following the Solid State Sciences Committee Spring Forum on February 27 \\ Industrial Competitiveness and Consortia • High $\mathrm{T}_{\mathrm{c}}$ Superconducting Films for Electronic Applications • The Science Behind Semiconductor Processing: Advances in Plasma and CVD Research}

For information, call the Materials Research Society at (412) 367-3003; FAX (412) 367-4373. 